\title{
MJN THE RELATIONSHIP BETWEEN SELF-EFFICACY AND SELF-CARE IN TYPE 2 DIABETES MELLITUS PATIENTS
}

\author{
Aria Wahyuni* and Dian Ramayani \\ Nursing Departement, Universitas Fort De Kock, Indonesia \\ *Corresponding Author’s Email: ariawahyuni@fdk.ac.d
}

\begin{abstract}
Self-Efficacy is needed to form self-care to prevent complications from type 2 diabetes mellitus. The purpose of the study was to assess the relationship between self-efficacy and self-care in type 2 diabetes mellitus patients. A descriptive correlation was used in this study. The Diabetes Management Self Efficacy Scale (DMSES) was used to measure self-efficacy and the Summary of Diabetes Self-Care Activities Measure (SDSCA) to measure self-care survey instrument were distributed to type 2 diabetes mellitus patient in one of internist outpatient Bukittinggi $(\mathrm{N}=81)$ form October 2018-August 2019. The results showed that mean self-efficacy of respondents was 88.65 and the self-care was 3.2. Statistical significance corelation was found between selfeficacy and self-care $(r=0.713 ; p=0.001)$. The study adds knowledge regarding health education. Further study is needed to explore other factors related to self-efficacy and self-care of type 2 diabetes mellitus to prevent complication.
\end{abstract}

Keywords: Self-care, Self-eficacy, Type 2 Diabetes Mellitus

\section{INTRODUCTION}

Diabetes mellitus is a group of metabolic diseases characterized by hyperglycemia that occurs due to abnormalities in insulin secretion, insulin action or both (Perkeni, 2015). Based on World Health Organization (WHO) data globally there were 422 million adults living with diabetes in 2014, this figure has almost doubled compared to 1980 from $4.7 \%$ to $8.5 \%$ (WHO, 2016). In 2017 the prevalence of diabetes mellitus becomes 451 million people worldwide and it is estimated that in 2045 it will increase to 693 million people living with diabetes mellitus. In Southeast Asia the prevalence of diabetes mellitus in 2017 was 82 million people and is estimated in 2045 to increase $84 \%$ to 151 million people living with diabetes mellitus. Indonesia is ranked sixth in the world with a total of 10.3 million people living with diabetes mellitus and it is estimated that in 2045 the figure will increase to 16.7 million (Cho et al., 2017). Based on the Ministry of Health's basic health research the percentage of diabetes mellitus prevalence in Indonesia in 2013 was $1.5 \%$ to $2.0 \%$ in 2018 . West Sumatra is one of the provinces in Indonesia with increased percentage of diabetes mellitus prevalence from $1.3 \%$ in 2013 to $1.5 \%$ in 2018. In the city of Bukittinggi, West Sumatra, diabetes is the second most common disease after hypertension (Kemenkes, 2013; Indonesian Ministry of Health, 2018).

Diabetes mellitus is a chronic disease that is complex and requires ongoing medical care. About $75 \%$ of people with diabetes mellitus experience death due to vascular complications. Other complications that can occur due to diabetes mellitus are heart disease, stroke, kidney failure, amputation due to diabetes mellitus sores, even leading to death. To prevent the development of complications that occur in people with diabetes mellitus, they need to learn and maintain self-management behavior for life, including self-care related to health care and daily life (Sari, 2018). One strategy used is to reduce multifactorial risk is by controlling blood glucose levels so that acute and chronic complications can be prevented among diabetes mellitus patients. This can be done by applying self-care management and providing support (ADA, 2019).

According to Orem on 1971, self-care is a human need for self-care conditions and self-care which is carried out by the individual itself continuously in an effort to meet the needs in maintaining the life, health and well-being of individuals both in a healthy and sick condition. Diabetes self-care is an independent action 
taken by diabetic patients in their daily lives with the aim of controlling glucose blood which includes activities to regulate diet (diet), physical activity (exercise), monitoring glucose blood, taking medication and foot care (Kusniawati, 2011). Instruments to measure selfcare for patients with diabetes mellitus consist of 15 question that is measured in seven days measuring diet, activity, foot care, blood glucose measurement, and medication (Toobert, Hampson \& Glasgow, 2000). Selfcare behavior of patients with type 2 diabetes mellitus has not been fully carried out. Activities such as diet control, physical activity, and medication are good, but in the activities of foot care and self-control of blood glucose the patient's care is still low (Sulistria, 2013). The mean patient with type 2 diabetes mellitus who did optimal self-care was 4.9 days after being discharged from the hospital while self-care activities that were still low were independent glucose blood monitoring and foot care (Kusniawati, 2011).

The successful management of diabetes mellitus depends on information about type 2 diabetes mellitus and the patient's self-efficacy for self-care in controlling psychological symptoms and complications. Self-efficacy is an individual's belief in his ability to perform self-care tasks so that the goal can be achieved well. Self-efficacy has a very important role in determining the success of treatment in most chronic diseases (Ariani, 2011). Selfeficacy is described as people's belief in their capability to organize and execute the course of action required to deal with prospective situations. Self-eficacy is a central concept in Bandura's social cognitive theory (which used to be called the social learning theory). In this theory it is supposed that people have self-motivating, self-reflecting, creative and self-steering possibilities, which enable them to have some control over their thoughts, feelings and actions. Self-efficacy instrument of type 2 diabetes mellitus patients were with 15 items related to selfconfidence which consisted of self-confidence in dieting, activity and exercise, caring for the feet, checking blood glucose and managing medication (Sturt, Hearnshaw \& Wakelin, 2010) .

Based on the results of research from of 40 respondents showed that people who have high selfefficacy are better at performing self-care for diabetes mellitus management compared to respondents with less self-efficacy in this case related to dietary compliance in patients with diabetes mellitus (Ningsih, Bayhakki \& Woferst, 2017). Research on 89 respondents showed that there was a significant relationship between selfefficacy and blood glucose levels in patients with type 2 DM (Firmansyah, 2018). The results of this study are in line with the study of 507 tertiary hospital respondents in India showing a strong positive relationship between self-efficacy and controlled glycemic status, with selfefficacy being the strongest determinant of glycemic status (Venkataraman et al., 2012). A study among 43 respondents with type 2 diabetes mellitus showing the results that there was a significant relationship between self-efficacy and self-care in patients with Type 2 diabetes (Asrikan, 2016). Research on 190 respondents also shows the results that there is a significant relationship between self-efficacy and self-care in patients with type 2 diabetes mellitus (Sari, 2018).

\section{METHODOLOGY}

\section{Study design}

Correlation studies are used to determine the relationship of self-efficacy and self-care in patients with type 2 diabetes with a cross sectional approach used in this study. The survey will be conducted from December 2018 until August 2019.

\section{Subject}

Respondents were recruited from internist outpatient hospitals in one of Bukittinggi West Sumatera Indonesia with 81 patients fulfilling the sample criteria. The sample criteria selected were (1) Diagnosis of Type 2 diabetes mellitus, (2) no activity inhibition, (3) no cognitive impairment, (4) no severe complication from diabetes mellitus.

\section{Measurement}

The Diabetes Management Self Efficacy Scale (DMSES) was used to measure self-efficacy (Sturt et al., 2010) and the Summary of Diabetes Self-Care Activities Measure (SDSCA expanded) to measure self-care (Toobert et al., 2000). The original instrument developer was communicated and permission was received to use and translate in Indonesian language. Both instruments were translated into Indonesian and then translated back into English. The translate process is carried out at the campus language institute with people who already have expertise in English. After the translate process, the instrument was tested to determine the reliability and validity of 30 patients with diabetes mellitus so that the final version was ready for use.

The Diabetes Management Self Efficacy Scale (DMSES) consists of 15 items of statements related to describing the confidence of patients with type two diabetes, each item is answered using a $0-10$ scale with the answer range: cannot do at all (0-4), maybe yes / maybe no (5-6) and certain can do (7-10). There are 3 
items of statements about controlling blood glucose, 7 items about managing diet, 1 item about foot care, 2 physical activities or exercise, 2 items for medication. Hypothesis that individual patient total scores $0-50=10$ w self-efficacy, 51-100=moderate self-efficacy and 101$150=$ high self-efficacy. The instrument was tested for Validity and the Croncbach alpha value of 0.985 was obtained so that the instrument was declared valid, and the reliability test was performed for each question item which obtained a value of $r>0.54$ ( $r$ table) so that all question items were declared reliable.

The Summary of Diabetes Self-Care Activities Measure (SDSCA) questions are used to measure the selfcare of diabetic patients in the last 7 days (0-7 days). There are 2 questions measuring general diet, 3 specific diet questions, 2 physical activity and execution questions, 2 blood glucose testing questions, 4 foot care questions, 1 medication question. In question number 4, which is about consuming high fat foods, the evaluation system is reversed to (7-0). The instrument was tested for Validity and the Croncbach alpha value of 0.985 was obtained so that the instrument was declared valid, and the reliability test was performed for each question item which obtained a value of $r>0.54$ ( $\mathrm{r}$ table) so that all question items were declared reliable.

\section{RESULTS}

\section{Patient demographics}

The study consisted of total of 81 type 2 diabetes mellitus patients who met the criteria at the hospital outpatient. The mean age of patients was 51.30 years (range 39-71 years), most of them were male (61.7\%), the highest education was high school $(63 \%)$, mostly were married $(81.5 \%)$, mostly working $(50.6 \%)$, and the mean duration of diabetes is 5.37 years (range $0-19$ years).

Table 1: Demography related self-eficacy and self-care of the participant

\begin{tabular}{|c|c|c|c|c|c|c|}
\hline \multirow{2}{*}{ Demography } & \multirow{2}{*}{$\begin{array}{l}\text { Mean } \\
\text { (SD) }\end{array}$} & \multirow{2}{*}{ n (\%) } & \multirow{2}{*}{$\begin{array}{c}\text { Self Eficacy } \\
\text { Mean (SD) }\end{array}$} & \multirow{2}{*}{$\begin{array}{c}\text { Self Care } \\
\text { Mean (SD) }\end{array}$} & \multicolumn{2}{|c|}{$p$} \\
\hline & & & & & Self Eficacy & Self Care \\
\hline Age & $\begin{array}{c}51.30 \\
(8.2)\end{array}$ & & \multirow{6}{*}{$86.65(32.60)$} & \multirow{6}{*}{$\begin{array}{c}3.21 \\
(0.53)\end{array}$} & 0.04 & 0.70 \\
\hline $\begin{array}{l}\text { Gender } \\
\text { Male } \\
\text { Female }\end{array}$ & & $\begin{array}{l}50(61.7) \\
31(38.3) \\
\end{array}$ & & & 0.39 & 0.37 \\
\hline $\begin{array}{l}\text { Education } \\
\text { Middle School } \\
\text { High School } \\
\text { College }\end{array}$ & & $\begin{array}{l}5(6.2) \\
51(63) \\
25(30.9)\end{array}$ & & & 0.64 & 0.67 \\
\hline $\begin{array}{l}\text { Marital Status } \\
\text { Merried } \\
\text { Widowed }\end{array}$ & & $\begin{array}{l}66(81.5) \\
15(18.5)\end{array}$ & & & 0.03 & 0.38 \\
\hline $\begin{array}{l}\text { Ocupation } \\
\text { Yes } \\
\text { No }\end{array}$ & & $\begin{array}{l}44(50.6) \\
37(45.7)\end{array}$ & & & 0.04 & 0.62 \\
\hline Years of Diabetes & $5.37(4.0)$ & & & & 0.02 & 0.34 \\
\hline
\end{tabular}

Table 2: Self-Eficacy, Self-Care of partcipant and pearson corelation

\begin{tabular}{|c|c|c|c|c|}
\hline \multicolumn{2}{|l|}{ Variables } & Mean (SD) & $r$ & $p$ \\
\hline Self Eficacy & \begin{tabular}{|l|} 
Diet \\
Exercise \\
Glucose Test \\
Foot Care \\
Medication \\
\end{tabular} & $\begin{array}{|cc|}88.65 & (23.60) \\
5.70 & (1.78) \\
5.78 & (1.54) \\
4.79 & (2.20) \\
7.86 & (0.91) \\
6.49 & (0.91) \\
\end{array}$ & & \\
\hline Self Care & $\begin{array}{l}\text { General Diet } \\
\text { Specific diet } \\
\text { Exercise } \\
\text { Glucose Test } \\
\text { Foot Care } \\
\text { Medication }\end{array}$ & $\begin{array}{ll}3.21 & (0.53) \\
4.65 & (1.37) \\
4.09 & (0.79) \\
2.88 & (1.24) \\
0.38 & (0.49) \\
3.12 & (0.57) \\
4.43 & (2.28)\end{array}$ & 0.713 & 0.001 \\
\hline
\end{tabular}

\section{Demographics related to self-efficacy and self-care}

The mean total self-efficacy was 86.65 (moderate self-efficacy) and the mean self-care was 3.21 days. From each demographic variable associated with selfefficacy and self-care, it was found that there was a significant relationship between age, marital status, occupation and duration of diabetes mellitus with selfefficacy ( $p=0.04,0.03,0.04$ and 0.02 ) but not significant with gender and education. While demographics associated with self-care showed that all demographic variables had no significant relationship with self-care.

\section{The relationship between self-efficacy and self-care}

The mean total self-efficacy is 88.65 (range 42-120)

70 | VOL. 11(3) January 2020 | THE MALAYSIAN JOURNAL OF NURSING 
if categorized as a total it is included in moderate selfefficacy with a range of low-high self-efficacy. Selfefficacy is divided into five points: diet with mean of 5.70 (range 2-8), physical activity or exercise 5.78 (range 3-8), glucose test 4.79 (range 1-8), foot care 7.89 (range 6-10) and medication 6.49 (range 5-8).

The mean total self-care of 3.21 days (0.24-4.27) means that the self-care of type 2 diabetes mellitus patients is still low. Self-care is divided into six points: general diet with mean of 4.65 days (range 2-7), specific diet 4.09 days (range 2.33-5.67), exercise or physical activity 2.88 days (range $0-4$ ), glucose blood test 0.39 days (range $0-1$ days), foot care 3.12 days (range 2-5 days), and medication 4.43 days (range $0-7$ ).

Further statistical test results using the Pearson correlation ( $r$ value) obtained $r=0.731$ means that there is a strong relationship, the higher the self-efficacy, the better self-care in patients with type 2 diabetes mellitus. The $p$ value obtained 0.001 where there is a significant relationship between self-efficacy and self-care in patients with type 2 diabetes mellitus.

\section{DISCUSSION}

\section{Demographic data}

The results of this study are in accordance with Karimy, Koohestani \& Araban (2018) that showed significant relationship between marital status, employment, duration of diabetes mellitus with selfefficacy but not for self-care. Gender wise there is a significant relationship between sex and self-efficacy but there is no relationship with self-care. This study found that there was no relationship between education and self-efficacy and self-care, but in Karimy, Koohestani \& Araban (2018) there was a relationship between education and self-efficacy but not for self-care. The duration of diabetes mellitus has a positive relationship with self-efficacy (Dehghan et al., 2017).

\section{Diet}

The diet in this study which focuses on self-efficacy states its ability for diet management for diabetes mellitus patients while the diet which focuses on selfcare is applying the diet for a week. The average statement of a patient in self-efficacy shows that the ability of the patient may be yes or may be no in diet management but at the time of arrival the patient can manage diet only for 4 days. Food control in Indonesia based on 2018 basic health research is a priority dietary arrangement (Indonesian Ministry of Health, 2018).

Previous research has shown that the attitude of patients in managing a diet is more beneficial than medication adherence because diet reduces complications of diabetes mellitus patients. Practice in applying the diet in patients with diabetes mellitus is influenced by important factors such as cultural background and dietary knowledge. The intended knowledge is related to an understanding of food guidelines so that they can influence food selection guidelines. It was further explained that in Indonesia, a study was conducted to measure dietary practices among diabetes mellitus patients, preferring to consume high-fat foods which caused an increased risk of CVD (Sami et al., 2017). This was proven in this study on item 4 of the self-care diet question of consuming high fat.

Diabetes mellitus patients generally do not complain regarding the management of their own diet (Jaworski et al., 2018). Sabbah \& AlShehri (2014) in his research on the application of self-management of diabetic patients specifically to diets mentioned $41.7 \%$ followed the diet well, it was even reported that patients were more obedient to follow treatment compared to adherence to the diet.

\section{Physical activity or Exercise}

Physical activity or exercise of diabetes mellitus patients in this study found that patients have high confidence in the category maybe yes or maybe no in doing activities, but the application of self-care for patients ranging between 0-4 days shows that there are some patients still low in physical activity or exercise. In the statement of self-efficacy, the value of the ability or self-confidence of patients for doing physical activity or exercise is categorized high while the patient's self-care questions show that most of the patient never do activities such as swimming, biking and walking. Patients carry out daily activities more at home.

Physical exercise or exercise is one of the controls against diabetes mellitus, data in West Sumatra shows that there are $50 \%$ of diabetes mellitus patients who show diabetes patients do exercise (Indonesian Ministry of Health, 2018). Participation in regular physical activity increases blood glucose control and can prevent or delay type 2 diabetes mellitus, along with lipids, blood pressure, cardiovascular events, mortality, and quality of life, reducing the risk of type 2 diabetes by $58 \%$ in high risk and increased action of insulin (Colberg et al., 2010; Sigal et al., 2006).

Some current research provides credible evidence that walking prevents type 2 diabetes mellitus and reduces the risk of cardiovascular events and / or death. 
More specifically, previous studies have suggested brisk walking for at least $30 \mathrm{~min} /$ day (eg, $\geq 15$ MET-hours per week) (Hamasaki, 2016). The important role of physical activity is seen as a high priority in improving health and preventing disease, it is recommended individual physical activity for 30 minutes for most of the days in a week. It is known that decreased activity increases obesity and decrease the rate of metabolism so that hyperglycemia occurs (Sigal et al., 2006). Diabetics (including elderly people) should exercise at least twice a week and preferably 3 times a week (Colberg et al., 2010)

\section{Blood Glucose Test}

Among the five self-efficacy points the lowest average was on the glucose blood test points, in which patients expressed no confidence in taking blood glucose measurements. Likewise for self-care the average blood glucose patient never take a glucose blood test for weeks.

Only $1.8 \%$ of the people of Indonesia check blood glucose, the rest do not perform routine check, as much as $85.5 \%$ have never even checked blood glucose. This pattern is similar in the province of West Sumatra, where routine blood glucose checks are done by $1.1 \%$ and $87.6 \%$ have never checked blood glucose.

Self-monitoring of blood glucose in diabetes management plays an important role in many ways such as assisting in achieving the target of controlling blood glucose every day, besides motivating patients to carry out diabetes mellitus self-care (Schnell, Hanefeld, \& Monnier, 2014). Self-monitoring of blood glucose can improve glycemic control among patients with type 2 diabetes mellitus who manage without insulin, improve quality of life, reduce complications and even death (McIntosh et al., 2010) (Hou et al., 2014). Patients who perform better self-care and report self-efficacy is also better in diabetes management as is evidenced by better blood glucose control (Lee, Ahn \& Kim, 2009). Selfmonitoring of blood glucose is effective in improving glycaemic control in type 2 diabetes (Zhu, Zhu \& Leung, 2016).

\section{Foot Care}

The highest self-efficacy is taking care of the feet or checking the feet themselves to prevent wound. But the act of doing self-care related to foot care is only done in 3.12 days. The self-efficacy indicator in foot care is the ability to examine the foot for injuries and the patients can do this. Self-care indicator in foot care involves seven-day activity including checking feet, looking at the shoes, washing feet, soaking feet and drying feet after washed. But on an average most of the patients never notice the quality of the shoes.

Regarding the prevalence of diabetic foot injuries in Indonesia, 25\% occur in home care settings (Yusuf, 2015). Foot care includes measurement of foot temperature, use of therapeutic footwear and the presence of health education as a form of increasing the ability and confidence in performing foot care (Netten et al., 2016)

Several studies have found that foot care in the majority of patients with diabetes mellitus is rarely done due to lack of knowledge about how to treat feet, and inability to practice foot care. After health education was conducted there was an increase in knowledge, willingness and motivation to learn to care for the feet (Nemcová \& Hlinková, 2014; Muhammad-Lutfi, Zaraihah \& Anuar-Ramdhan, 2014; Bonner, Foster \& Spears-Lanoix, 2016). Foot self-care is significantly higher in patients who have received advice on foot care and in those whose feet have been examined by a doctor at least once (Chiwanga \& Njelekela, 2015). No significant correlation was identified between the level of selfefficacy and the performance of foot care behavior. Statistical significance was found between foot care behavior and sex with male scores being higher than women (Wendling \& Beadle, 2015). Factors related to foot care behaviors include gender, history of foot injuries, nephropathy, disease perception and belief in health benefits (Usta et al., 2019)

\section{Medication}

Regarding the patient's statement in self-efficacy about the ability of self-confidence in treatment, average patient answered that they were able to do so but in the application of self-care in treatment of patients they can only undergo this procedure for an average of 4 days.

Basic health research in Indonesia states that the number of diabetes mellitus patients in Indonesia receiving anti-diabetes drugs and insulin injections or a combination of both as much as $90.7 \%$ and specifically West Sumatra as much as $88.4 \%$. The compliance rate for taking drugs in Indonesia reaches $90.56 \%$ while in West Sumatra it is around $88.8 \%$ who complains to take medication or injecting insulin. Mostly, the reason stated by patients for compliant to take medicine, especially in West Sumatra is feeling healed $(43.36 \%)$, followed by other reasons such as taking traditional medicine (39.65\%), not routinely seeking treatment (39.25\%), often forgetting to take medicine $(29.52 \%)$, could not stand the side effects of drugs $(14.07 \%)$ and other reasons $(12.08 \%)$, like unable to buy drugs (3.96\%), and drugs were not available in health care facilities $(0.56 \%)$ (Indonesian Ministry of Health, 2018). 
The percentage of medication adherence becomes strong as this foundation of adherence of the patients with diabetes mellitus contributes shape their confidence. Factors associated with poor adherence to treatment with major non-patient factors (for example, lack of integrated care in many health care systems and clinical inertia among health care professionals), patient demographic factors (for example, young age, education level low, and low-income levels). Therefore it is important for the patients' to keep beliefs about their medications (eg, perceived treatment inefficiency), and the perceived burden of patients regarding obtaining and taking their medicines (for example, treatment complexity, unreachable costs, and hypoglycemia) (Polonsky \& Henry, 2016). These factors are related to the level of compliance with work status, current medication, HBA1C, and the number of comorbidities associated (Alqarni et al., 2019). Lower adherence is associated with younger age, number of drugs, HbAlc levels, scheduling drug intake, inability to develop habitual behavior, role models, the influence of family support and gaps in knowledge about diabetes and its management with drugs (Aloudah et al., 2018) .

\section{Self-efficacy and self-care for type $\mathbf{2}$ diabetes mellitus patients}

The results showed mean total self-efficacy of 88.65 when categorized as total entered into moderate selfefficacy with a range of low-high self-efficacy. The mean total self-care of 3.21 days means that the self-care of patients with diabetes mellitus is still low. The higher selfefficacy, the better sef-care in diabetes mellitus patients.
Masoompour, Tirgari \& Ghazanfari, (2017) in his research found a significant positive correlation between self-efficacy and self-care in other words increasing selfefficacy in diabetic patients can improve self-care behavior, according to Bandura's self-efficacy theory perception of self-efficacy is an important factor that contributes towards behavioral success. Patients with higher self-care scores have better self-efficacy, social support, and attitudes towards self-care (Karimy et al., 2018). Patients with well-controlled diabetes will be confident in choosing the right foods when hungry and their ability to exercise for 15-30 minutes, four to five times per week (Beckerle \& Lavin, 2013). The strongest predictor of diabetes self-management was treatment, followed by perceived self-efficacy (Kurnia, Amatayakul \& Karuncharernpanit, 2017).

\section{CONCLUSION}

Good self-efficacy affects self-care behavior, increased self-efficacy by approaching cognitive functions, namely providing health education about selfcare management and health education that presents social or family support. Health education is provided starting from the order of primary, secondary and tertiary health services. Further research is directed at health education in self-management in the form of innovation as well as exploring other factors related to self-efficacy and self-care and in large sample sizes.

\section{ACKNOWLEDGEMENTS}

The authors gratefully acknowledge the all of type 2 diabetes mellitus in internist outpatient, head of STIKes Fort De Kock and Director of hospital Bukittinggi.

\section{REFERENCES}

American Diabetes Association (ADA) (2019). Introduction: Standards of Medical Care in Diabetes 2019. Diabetes Care, 42(Supplement 1), S1-S2.

Aloudah, N.M., Scott, N.W., Aljadhey, H.S., Araujo-Soares, V., Alrubeaan, K.A. \& Watson, M.C. (2018). Medication adherence among patients with type 2 diabetes: A mixed methods study. PLOS ONE, 13(12), pp 1-18.

Alqarni, A.M., Alrahbeni, T., Al Qarni, A. \& Al Qarni, H.M. (2019). Adherence to diabetes medication among diabetic patients in the Bisha governorate of Saudi Arabia - a cross-sectional survey. Patient Preference and Adherence, 13, pp 63-71.

Ariani, Y. (2011). Hubungan Antara Motivasi Dengan Efikasi Diri Pasien Dm Tipe 2 Dalam Konteks Asuhan Keperawatan Di Rsup. H. Adam Malik Medan. Thesis submitted to Universitas Indonesia, Indonesia.

Asrikan, M.A. (2016). Relationship of Self Efficacy with Self Care Activity in Patients with Type 2 Diabetes Mellitus in Pandan Arang Boyolali Hospital. Bachelor of Nursing Program (S-1), School of Health Sciences, STIKes Kusuma Husada. Retrieved from: http://digilib.stikeskusumahusada.ac.id/files/disk1/33/01-gdl-muhammadar -1607-1artikel-n.pdf

Beckerle, C.M. \& Lavin, M.A. (2013). Association of self-efficacy and self-care with glycemic control in diabetes. Diabetes Spectrum, 26(3), pp 172-178. 
Bonner, T., Foster, M. \& Spears-Lanoix, E. (2016). Type 2 diabetes-related foot care knowledge and foot self-care practice interventions in the united states: A systematic review of the literature. Diabetic Foot and Ankle, 7:29758.

Chiwanga, F.S. \& Njelekela, M.A. (2015). Diabetic foot: Prevalence, knowledge, and foot self-care practices among diabetic patients in Dar es Salaam, Tanzania - a cross-sectional study. Journal of Foot and Ankle Research, 8(1), pp $1-7$.

Cho, N.H., Kirigia, J., Claude, J., Mbanya, Ogurstova, K. \& Guariguata, L. (2017). IDF Diabetes Atlas. IDF Diabetes Atlas, 18th edition. International Diabetes Federation. Retrived from: http://fmdiabetes.org/wp-content/ uploads/2018/03/IDF-2017.pdf

Colberg, S.R., Sigal, R.J., Fernhall, B., Regensteiner, J.G., Blissmer, B.J., Rubin, R.R., Chasan-Taber, L., Albright, A.L., Braun, B.; American College of Sports Medicine; American Diabetes Association. (2010). Exercise and type 2 diabetes: The American College of Sports Medicine and the American Diabetes Association: Joint position statement. Diabetes Care, 33(12).

Dehghan, H., Charkazi, A., Kouchaki, G. M., Zadeh, B.P., Dehghan, B.A., Matlabi, M., Mansourian, M., Qorbani, M., Safari, O., Pashaei, T. \& Mehr, B.R. (2017). General self-efficacy and diabetes management self-efficacy of diabetic patients referred to diabetes clinic of Aq Qala, North of Iran. Journal of Diabetes and Metabolic Disorders, 16(1), pp $10-14$.

Firmansyah, M.R. (2018). The Relationship of Self-Efficacy with Blood Glucose of Type 2 Diabetes Mellitus in 7 Ulu Heath Centre Palembang. Journal 'aisyiyah Medikaedika, 1(1), pp 1-7.

Hamasaki, H. (2016). Daily physical activity and type 2 diabetes: A review. World Journal of Diabetes, 7(12), pp 243251.

Hou, Y.Y., Li, W., Qiu, J.B. \& Wang, X.H. (2014). Efficacy of blood glucose self-monitoring on glycemic control in patients with non-insulin-treated type 2 diabetes: A meta-analysis. International Journal of Nursing Sciences, 1(2), pp 191-195.

Indonesian Ministry of Health (2018). National Institute of Health Research and Development. Population Health Basic Health Research. Indonesia Jakarta: Ministry of Health Republic of Indonesia Jakarta.

Jaworski, M., Panczyk, M., Cedro, M. \& Kucharska, A. (2018). Adherence to dietary recommendations in diabetes mellitus: Disease acceptance as a potential mediator. Patient Preference and Adherence, 12, pp 163-174.

Karimy, M., Koohestani, H.R. \& Araban, M. (2018). The association between attitude, self-efficacy, and social support and adherence to diabetes self-care behavior. Diabetology and Metabolic Syndrome, 10(1), pp 1-6.

Kemenkes. (2013). Health Basic Research Result. Jakarta.

Kurnia, A.D., Amatayakul, A. \& Karuncharernpanit, S. (2017). Predictors of diabetes self-management among type 2 diabetics in Indonesia: Application theory of the health promotion model. International Journal of Nursing Sciences, 4(3), pp 260-265.

Kusniawati (2011). Analysis of Contributing Factors to Diabetes Self Care in Type 2 Diabetes Client in Tangerang Hospital. Lontar UI. Universitas Indonesia.

Lee, H., Ahn, S. \& Kim, Y. (2009). Self-care, self-efficacy, and glycemic control of Koreans with diabetes mellitus. Asian Nursing Research,3(3), pp 139-146.

Masoompour, M., Tirgari, B. \& Ghazanfari, Z. (2017). The relationship between health literacy, self-efficacy, and selfcare behaviors in diabetic patients. Evidence Based Care Journal, 7(3), pp 17-25.

McIntosh, B., Yu, C., Lal, A., Chelak, K., Cameron, C., Singh, S. R. \& Dahl, M. (2010). Efficacy of self-monitoring of blood glucose in patients with type 2 diabetes mellitus managed without insulin: A systematic review and metaanalysis. Open Medicine, 4(2), pp 102-113.

Muhammad-Lutfi, A., Zaraihah, M. \& Anuar-Ramdhan, I. (2014). Knowledge and Practice of Diabetic Foot Care in an In- Patient Setting at a Tertiary Medical Center. Malaysian Orthopaedic Journal, 8(3), pp 22-26. 
Nemcová, J. \& Hlinková, E. (2014). The efficacy of diabetic foot care education. Journal of Clinical Nursing, 23(5-6), pp 877-882.

Netten, J.J. Van, Price, P.E., Lavery, L.A., Monteiro-S0ares, M., Rasmussen, A., Jubiz, Y. \& Bus, S.A. (2016). Prevention of Foot Ulcers in the at-risk patient with diabetes : a systematic review. Diabetes/Metabolism Research and Reviews, 32(Suppl 1), pp 84-98.

Ningsih, H.R., Bayhakki, B. \& Woferst, R. (2017). Relationship of Self Efficacy to Diit Compliance in Patients with Diabetes Mellitus. Journal Online Mahasiswa (JOM)Bidang Ilmu keperawatan, 5, pp 212-219.

Orem, D.E. (1971). Nursing: concepts of practice. McGraw-Hill, New York.

Perkeni (2015). Consensus on the Management and Prevention of type 2 Diabetes in Indonesia 2011. Guideline by the Indonesian Society of Endocrinology (Perkeni)

Polonsky, W.H. \& Henry, R.R. (2016). Poor medication adherence in type 2 diabetes: Recognizing the scope of the problem and its key contributors. Patient Preference and Adherence, 10, 1299-1306.

Sabbah, K. \& AlShehri,A. (2014). Practice and perception of self - management among diabetics in Taif, KSA: Impact of demographic factors. International Journal of Medical Science and Public Health, 3(3), pp 277-284.

Sami, W., Ansari, T., Butt, N.S. \& Hamid, M.R.A. (2017). Effect of diet on type 2 diabetes mellitus: A review. International Journal of Health Science, 11(2), pp 39-51.

Sari, D.N. (2018). The Relationship between self -efficacy with self-care on type 2 diabetes melitus in outpatient M. Djamil Padang hospital. Universitas of Andalas, Indonesia.

Schnell, O., Hanefeld, M. \& Monnier, L. (2014). Self-monitoring of blood glucose: A prerequisite for diabetes management in outcome trials. Journal of Diabetes Science and Technology, 8(3), pp 609-614.

Sigal, R.J., Kenny, G.P., Wasserman, D.H., Castaneda-Sceppa, C. \& White, R.D. (2006). Physical activity/exercise and type 2 diabetes: A consensus statement from the American Diabetes Association. Diabetes Care, 29(6), pp $1433-1438$.

Sturt, J., Hearnshaw, H. \& Wakelin, M. (2010). Validity and reliability of the DMSES UK: A measure of self-efficacy for type 2 diabetes self-management. Primary Health Care Research and Development, 11(4), 374-381.

Sulistria, Y.M. (2013). Level of Self-care Outpatients Diabetes mellitus type 2 in Kalirungkut Health Center Surabaya. Journal Ilmiah Mahasiswa Universitas Surabaya, 2(2), 1-11.

Toobert, D.J., Hampson, S.E. \& Glasgow, R.E. (2000). The Summary of Diabetes Self-Care. Diabetic Care, 23(7), pp 943-950.

Usta, Y. Y., Dikmen, Y., Yorgun, S. \& Berdo, I. (2019). Predictors of foot care behaviours in patients with diabetes in Turkey. Peer J, 7, e6416.

Venkataraman, K., Kannan, A.T., Kalra, O.P., Gambhir, J.K., Sharma, A.K., Sundaram, K.R. \& Mohan, V. (2012). Diabetes self-efficacy strongly influences actual control of diabetes in patients attending a tertiary hospital in India. Journal of Community Health, 37(3), pp 653-662.

Wendling, S. \& Beadle, V. (2015). The relationship between self-efficacy and diabetic foot self-care. Journal of Clinical and Translational Endocrinology, 2(1), pp 37-41.

World Health Organization (2016). Global Report on Diabetes. Geneva, Switzerland. Retrieved from: http://apps.who.int/iris/bitstream/10665/204871/1/9789241565257_eng.pdf?ua=1\&utm_source=blog\&utm_camp aign=rc_blogpost

Yusuf, S. (2015). The urgency of research and publication of diabetic foot injuries in Indonesia. Journal Luka Indonesia, $1, \mathrm{pp} 1-2$.

Zhu, H., Zhu, Y. \& Leung, S.W. (2016). Is self-monitoring of blood glucose effective in improving glycaemic control in type 2 diabetes without insulin treatment: A meta-analysis of randomised controlled trials. BMJOpen, 6(9), pp 1-9. 